\title{
Prospective assessment of the decision-making impact of the Breast Cancer Index in recommending extended adjuvant endocrine therapy for patients with early-stage ER-positive breast cancer
}

\author{
Tara Sanft $^{1} \cdot$ Bilge Aktas $^{1} \cdot$ Brock Schroeder $^{2} \cdot$ Veerle Bossuyt $^{1} \cdot$ Michael DiGiovanna $^{1} \cdot$ \\ Maysa Abu-Khalaf ${ }^{1}$ - Gina Chung ${ }^{1}$ - Andrea Silber ${ }^{1}$ - Erin Hofstatter ${ }^{1}$. \\ Sarah Mougalian $^{1}$ - Lianne Epstein ${ }^{1}$ - Christos Hatzis ${ }^{1}$ - Cathy Schnabel ${ }^{2}$. \\ Lajos Pusztai ${ }^{1}$
}

Received: 4 September 2015/Accepted: 3 November 2015/Published online: 14 November 2015

(C) The Author(s) 2015. This article is published with open access at Springerlink.com

\begin{abstract}
Extended adjuvant endocrine therapy (10 vs. 5 years) trials have demonstrated improved outcomes in early-stage estrogen receptor (ER)-positive breast cancer; however, the absolute benefit is modest, and toxicity and tolerability challenges remain. Predictive and prognostic information from genomic analysis may help inform this clinical decision. The purpose of this study was to assess the impact of the Breast Cancer Index (BCI) on physician recommendations for extended endocrine therapy and on
\end{abstract}

Clinicaltrials.gov identifier: NCT02057029.

Tara sanft and Bilge Aktas are joint first authors.

Electronic supplementary material The online version of this article (doi:10.1007/s10549-015-3631-9) contains supplementary material, which is available to authorized users.

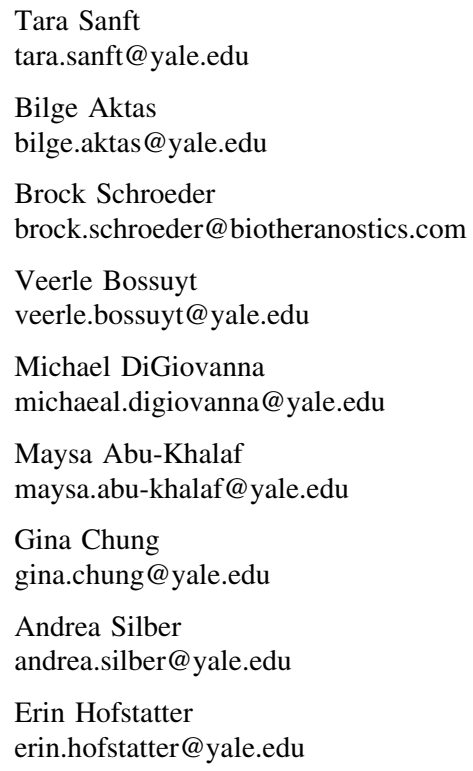

patient anxiety and decision conflict. Patients with stage IIII, ER-positive breast cancer who completed at least 3.5 years of adjuvant endocrine therapy were offered participation. Genomic classification with BCI was performed on archived tumor tissues and the results were reported to the treating physician who discussed results with the patient. Patients and physicians completed pre- and posttest questionnaires regarding preferences for extended endocrine therapy. Patients also completed the validated traditional Decisional Conflict Scale (DCS) and State Trait Anxiety Inventory forms (STAI-Y1) pre- and post-test. 96 patients were enrolled at the Yale Cancer Center [median age 60.5 years (range 45-87), $79 \%$ postmenopausal, $60 \%$ stage I). BCI predicted a low risk of late recurrence in $59 \%$ of patients versus intermediate/high in 24 and $17 \%$,

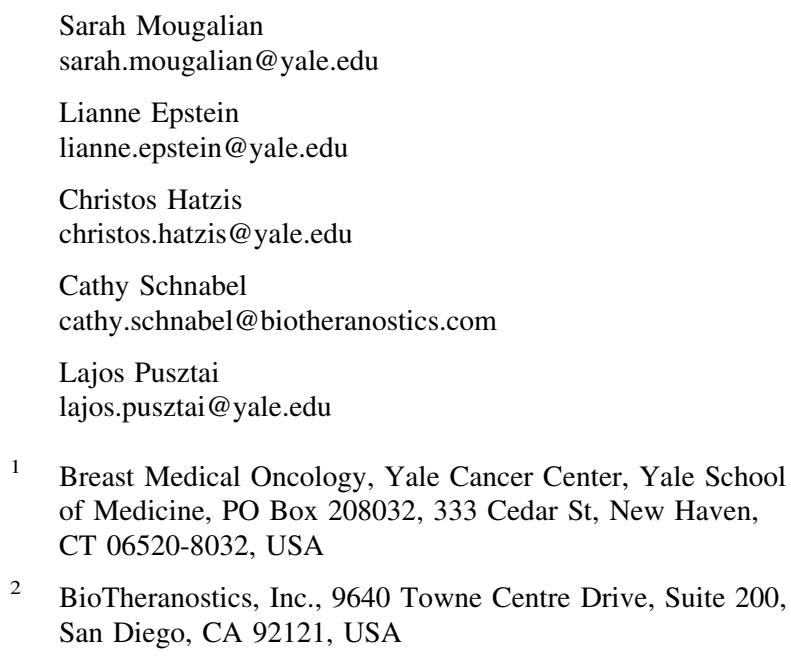


respectively. Physician recommendations for extended endocrine therapy changed for $26 \%$ of patients after considering BCI results, with a net decrease in recommendations for extended endocrine therapy from 74 to $54 \%$. After testing, fewer patients wanted to continue extended therapy and decision conflict and anxiety also decreased. Mean STAI and DCS scores were 31.3 versus $29.1(p=0.031)$ and 20.9 versus $10.8(p<0.001)$ pre- and post-test, respectively. Incorporation of BCI into risk/benefit discussions regarding extended endocrine therapy resulted in changes in treatment recommendations and improved patient satisfaction.

Keywords Hormone therapy - Late recurrence . Survivorship · Risk assessment · Anxiety · Satisfaction

$\begin{array}{ll}\text { Abbreviations } \\ \text { ER } & \text { Estrogen receptor } \\ \text { BCI } & \text { Breast Cancer Index } \\ \text { DCS } & \text { Decisional conflict scale } \\ \text { STAI } & \text { State Trait Anxiety Inventory } \\ \text { ROR } & \text { PAM50 risk of recurrence } \\ \text { H/I } & \text { HoxB13/IL17BR ratio } \\ \text { PR } & \text { Progesterone receptor } \\ \text { HIC } & \text { Human Investigations Committee } \\ \text { qRT-PCR } & \text { Quantitative reverse transcription polymerase } \\ & \text { chain reaction } \\ \text { FFPE } & \text { Formalin-fixed paraffin-embedded tissue }\end{array}$

\section{Introduction}

The risk of recurrence for many estrogen receptor (ER) positive breast cancers extends over a prolonged period of time and around $50 \%$ of all recurrences develop after the first 5 years of follow-up ("late recurrence") [1]. Importantly, extended adjuvant endocrine therapy can reduce the risk of late recurrences. In 5 different randomized controlled trials (NCIC-CTG MA.17, NSABP-B33, ABCSG6a, ATLAS, and aTTom), which investigated either aromatase inhibitors following an initial 5 years of tamoxifen [2-6] or 10 years of tamoxifen versus 5 years [7, 8], extended endocrine therapy reduced the risk of late disease recurrence. While these studies have established that extended endocrine therapy is superior to 5 years of adjuvant endocrine treatment; they also demonstrated that the absolute benefit from prolonged endocrine therapy is modest (approximately 3-5\% absolute benefit across studies) and comes with added toxicity. For example, in the ATLAS trial, 10 years of tamoxifen resulted in increased risk for pulmonary embolism (RR 1.87, $95 \%$ CI
1.13-3.07, $p=0.01$ ) and endometrial cancer (RR 1.74, $95 \%$ CI 1.30-2.34, $p=0.0002$ ) [7]. The cumulative risk of endometrial cancer during years $5-14$ was $3.1 \%$ for 10 years of tamoxifen compared to $1.6 \%$ for 5 years [7, 9]. Extended adjuvant therapy with aromatase inhibitors after tamoxifen also causes an increase in the risk for osteoporosis, which may lead to unfavorable serum lipid profiles, and is associated with arthralgias and menopause side effects $[4,10]$. In the MA17 trial, osteoporosis incidence was $8.1 \%$ in the letrozole group compared to $6 \%$ in controls $(p=0.003)$. Hot flashes, anorexia, arthralgia, myalgia were also statistically significantly more common in the letrozole arm [4]. Because of the modest efficacy, potential for adverse events, and costs of therapy, there is an unmet need for tools to help identify women who are at risk for late recurrence and have endocrine sensitive cancers and therefore would benefit the most from prolonged endocrine therapy $[11,12]$.

Clinical variable-based risk prediction models such as Adjuvant! Online predict cumulative risk of recurrence over a 10-year period but do not distinguish between risks for early versus late relapse [13]. Furthermore, analyses from the extended endocrine therapy clinical trials have shown that clinicopathologic factors, including tumor size, grade, nodal status, and quantitative ER are not predictive for benefit from endocrine therapy $[4,6,7,14]$. Recent studies suggested that the 21-gene recurrence score (RS) is most accurate to assess risk of recurrence in the first 5 years and is less useful to predict late recurrences [1518]. Several emerging molecular diagnostic assays including the EndoPredict test, the PAM50 risk of recurrence (ROR) score, and the Breast Cancer Index (BCI) tests have demonstrated the ability to specifically assess risk of late recurrence in ER-positive cancers [14, 19-22]. BCI is an 11-gene, gene-expression-based assay that incorporates both a proliferation component and an estrogen signaling component [19]. In addition to being validated in 2 randomized trial cohorts as a prognostic tool for risk of late recurrence, $\mathrm{BCI}$ also incorporates an endocrine response biomarker (HoxB13/IL17BR ratio [H/I]), which has been demonstrated in 3 randomized controlled trial cohorts to predict benefit from endocrine therapy [14, 19, 23]. BCI reports prognostic risk separately for early and late recurrence and also provides the likelihood of benefit from extended endocrine therapy based on the $\mathrm{H} / \mathrm{I}$ ratio. While the test has been clinically validated, to-date, there have not been studies to examine the clinical utility of the test on treatment recommendations for extended endocrine therapy. The primary objective of this study was to prospectively assess the impact of the BCI results on physicians' recommendation for extended adjuvant endocrine therapy and to assess its effect on patient decision conflict, anxiety, and satisfaction with the treatment recommendation. 


\section{Methods}

This study was approved by the Human Investigations Committee (HIC) and all participants signed informed consent.

\section{Patients}

All women with a history of ER or progesterone receptor (PR) positive, stage I-III breast cancer, who have completed at least 3.5 years of adjuvant endocrine therapy and were eligible for further extended adjuvant endocrine therapy were offered participation in the study. The research assistant identified eligible patients who were coming to the breast cancer clinic for routine follow-up. The research assistant alerted the treating physicians who then discussed the study with the patient. Both the patient and her treating physician had to agree to complete a pretest and a post-test questionnaire (Supplementary appendix). Patient information including demographic data, comorbid illnesses, breast cancer characteristics (TNM stage, histologic grade, ER, PR, and HER status) and treatment history including side effects from prior endocrine therapy was collected. Physicians were asked to estimate the patient's risk of recurrence, provide recommendation for extended endocrine therapy, and indicate confidence in the recommendation before testing and after BCI test results became available. Patients reported their perceived risk of recurrence, preference for extended adjuvant therapy and completed the State Trait Anxiety Index (STAI) and the traditional decision conflict scale (DCS) instruments before and after testing (Supplementary appendix). The STAI captures both transient anxiety (state anxiety) and more long-standing anxiety (trait anxiety) [24]. Participants in this study were asked to complete the state anxiety (STAI-Y1) form only as trait anxiety is not expected to be modifiable based on the knowledge of the BCI results. The STAI-Y1 questionnaire includes 20 items which are answered on a 1-4 scale, and the STAI-Y1 score ranges from 20 to 80 , with higher score correlating with greater anxiety [24]. The DCS includes 16 statements and 5 Likert-scale response categories that measure personal perceptions of uncertainty when choosing between options. The score ranges from 0 to 100 and higher scores indicate higher decisional conflict and greater difficulty in making a decision [25]. Patients were also queried for concerns of cost, side effects, safety and benefit, level of comfort with the choice of extended therapy before and after the BCI results, and impact on compliance. The median time between completion of the pre- and post-test surveys was 92.5 days (range $21-364$ ).

\section{Molecular testing}

$\mathrm{BCI}$ is an 11-gene, gene-expression-based (qRT-PCR) assay performed on formalin-fixed paraffin-embedded (FFPE) tissue (BioTheranostics; San Diego, CA). The BCI assay yields a composite score indicating an individualized percentage risk of late distant recurrence (post-5 years) and a categorical (high vs. low) likelihood of benefit from extended endocrine therapy. The assay represents the combination of two distinct predictors [19]. The first is a two-gene endocrine treatment sensitivity marker based on the ratio of HOXB13 and IL17BR expression (H/I) [26, 27], the second is a proliferation marker represented by the average expression of five cell cycle-associated genes BUB1B, CENPA, NEK2, RACGAP1, and RRM2 [27]. The two markers together comprise a proprietary score that ranges from 0 to 10 , which is associated with an individualized risk of late recurrence, and is categorized into low (BCI score $<5.1)$, intermediate $(5.1 \leq \mathrm{BCI}$ score $<6.5)$, and high-risk (BCI score $\geq 6.5$ ) groups using previously validated cut-points (note: the intermediate and high-risk groups have similar risk of late recurrence in validation studies) [19]. The BCI report includes 2 distinct elements: an individualized risk of late (5-10 years) distant recurrence and a prediction of likelihood of benefit from extended endocrine therapy based on the $\mathrm{H} / \mathrm{I}$ biomarker. While the assay provides an individualized assessment of risk between years 5-10, data from one validation study did show significant prognostic ability to year 15 post-diagnosis [19]. The BCI test was performed on archived tumor tissues (primary tumor core biopsy or resection specimen) and results were reported to the treating physician who discussed results with the patient.

\section{Statistical considerations}

No prior data exist that describe the impact of the BCI results on physician decision-making, therefore, we assumed a recommendation change rate of $25 \%$ (i.e., change from pre-test recommendation of no extended therapy to post-test recommendation of extended therapy or vice versa) which is similar to change rates observed with Oncotype Dx. [28] The study was designed with a sample size of 100 patients to allow estimation of this change rate within an exact binomial $95 \%$ confidence interval half-width of $9 \%$. Data on physicians' confidence and patients' comfort level regarding the treatment recommendation before and after BCI testing were compared using McNemar's test for paired data; odds ratios (OR) were estimated by conditional logistic regression. The preand post-test average DCS and STAI scores were compared using a paired $t$ test. 


\section{Results}

\section{Patient and tumor characteristics}

Between February and August 2014, 153 consecutive patients with history of ER-positive, stage I-III breast cancer currently receiving adjuvant endocrine therapy for at least 3.5 years were screened for eligibility at the Breast Center of Yale Cancer Center. Ninety-six patients met all eligibility criteria, agreed to participate in the study, and had sufficient tissue for testing. All 96 patients completed both the pre-and post-test surveys. Figure 1 shows the CONSORT diagram and Table 1 presents the patient characteristics. The median age was 60.5 years (range 45-87), 70 patients had node negative disease, 58 had stage I disease, and 49 patients received adjuvant or neoadjuvant chemotherapy. Thirty patients were receiving adjuvant tamoxifen and the rest an aromatase inhibitor when they entered the study. Thirty patients had normal bone density, and 49 had osteopenia on their most recent bone density measurements within a year of study entry.

\section{Summary of BCI test results}

BCI categorized 57 patients as low risk, 23 as intermediate risk, and 16 as high risk for late distant recurrence, while 56 and 40 patients were predicted to have low likelihood and high likelihood of benefit from extended endocrine therapy, respectively. The combinations of prognostic and predictive categorizations are shown in supplementary Table 1 . In 43 cases, the assay predicted low risk of late recurrence and a low likelihood of benefit from extended endocrine therapy, while in 26 cases, the assay predicted a high or intermediate risk of late recurrence and high likelihood of benefit from extended endocrine therapy. In 13 cases, patients had high or intermediate prognostic risk, but no predicted benefit from extended endocrine therapy (Supplementary Table 1).

\section{Impact of BCI results on physician decision-making}

Prior to the BCI test results, treating medical oncologists assessed $49 \%$ of patients to be low risk for recurrence (defined as less than $5 \%$ risk of recurrence after 5 years of endocrine therapy). An additional $38 \%$ were considered as intermediate risk (i.e., predicted risk of recurrence 6-15\%) and the remaining $13 \%$ as high risk based on physician's judgment. The distribution of subjective risk estimates by physicians with corresponding BCI results are shown in Table 2. Prior to BCI testing, physicians recommended extended endocrine therapy to the majority of patients (71 of 96 patients, $74 \%$ ) (Fig. 2). When extended endocrine therapy was not recommended, the main reason was perceived low risk of recurrence $(n=22)$ followed by risk of osteoporosis $(n=4)$ and side effects from therapy $(n=3)$.

Following BCI testing, physicians changed treatment decisions for 25 patients (26\%), Extended adjuvant therapy was recommended to $52(54 \%)$ of patients, a statistically significant reduction $(\mathrm{OR}=0.14 ; 95 \% \quad \mathrm{CI}$ $0.04-0.46 ; p=0.0003$; Fig. 2). The majority of the changes were in patients with low risk of late recurrence and low likelihood of benefit. Changes in physician confidence

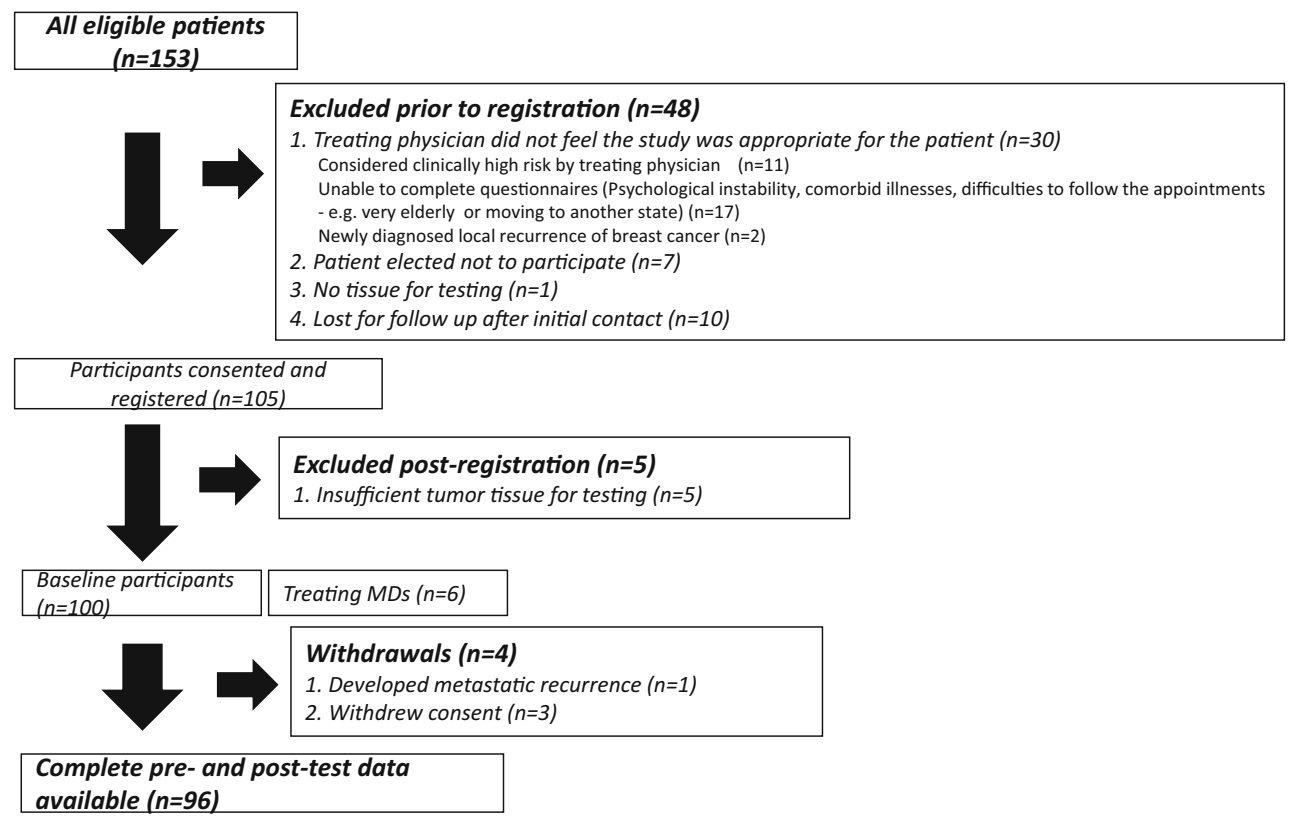

Fig. 1 Consort diagram of the participants 
Table 1 Patient and tumor characteristics

\begin{tabular}{|c|c|c|}
\hline Patient and tumor characteristics & $(\mathrm{n}=96)$ & $\%$ \\
\hline Median age (min-max) & $60.5(45-87)$ & \\
\hline$<50$ years old & 11 & 12 \\
\hline$\geq 50$ years old & 85 & 88 \\
\hline Caucasian & 87 & 91 \\
\hline African American & 5 & \\
\hline Asian & 2 & \\
\hline Not available & 2 & \\
\hline Premenopausal & 13 & 14 \\
\hline Postmenopausal & 76 & 79 \\
\hline Perimenopausal & 7 & 7 \\
\hline \multicolumn{3}{|l|}{ Receptor status } \\
\hline ER positive & 96 & 100 \\
\hline ER negative & 0 & \\
\hline PR positive & 85 & 88 \\
\hline PR Negative & 11 & 12 \\
\hline HER2 positive & 9 & \\
\hline HER2 negative & 86 & 90 \\
\hline HER2 not available & 1 & \\
\hline \multicolumn{3}{|l|}{ Histologic grade } \\
\hline Grade 1 & 30 & 31 \\
\hline Grade 2 & 50 & 52 \\
\hline Grade 3 & 16 & 17 \\
\hline \multicolumn{3}{|l|}{ TNM stage (AJCC) } \\
\hline Stage I & 58 & 60 \\
\hline Stage II & 33 & 35 \\
\hline Stage III & 5 & \\
\hline \multicolumn{3}{|l|}{ Tumor size at diagnosis } \\
\hline $\mathrm{T} 1(\leq 2 \mathrm{~cm})$ & 65 & 68 \\
\hline $\mathrm{T} 2(>2-5 \mathrm{~cm})$ & 32 & 33 \\
\hline $\mathrm{T} 3(>5 \mathrm{~cm})$ & 3 & \\
\hline T4 (skin involvement) & 0 & \\
\hline \multicolumn{3}{|l|}{ Nodal status at diagnosis } \\
\hline N0 (no nodal involvement) & 70 & 73 \\
\hline N1 (1-3 nodes) & 22 & 23 \\
\hline N2 (4-9 nodes) & 4 & 4 \\
\hline N3 (>9 or IC) & 0 & \\
\hline \multicolumn{3}{|l|}{ Chemotherapy } \\
\hline Adjuvant & 38 & 40 \\
\hline Neoadjuvant & 11 & 11 \\
\hline None & 47 & 49 \\
\hline \multicolumn{3}{|l|}{ Adjuvant endocrine therapy } \\
\hline Tamoxifen & 30 & 31 \\
\hline Aromatase Inhibitors & 66 & 69 \\
\hline Letrozole & 48 & 50 \\
\hline Anastrozole & 16 & 17 \\
\hline Exemestane & 2 & 2 \\
\hline \multicolumn{3}{|l|}{ Last bone density } \\
\hline Normal & 30 & 31 \\
\hline
\end{tabular}

Table 1 continued

\begin{tabular}{lcr}
\hline Patient and tumor characteristics & $(\mathrm{n}=96)$ & $\%$ \\
\hline Osteopenia & 49 & 51 \\
Osteoporosis & 5 & 5 \\
Not available & 12 & 13 \\
\hline
\end{tabular}

$n$ number of the patients, $E R$ estrogen receptor $P R$ progesterone receptor HER2 human epidermal growth factor receptor 2

are shown in Fig. 3. More physicians felt strongly confident in their recommendation after the test result $(24 \%)$ than before $(8 \%) \quad(\mathrm{OR}=4.75 ; 95 \%$ CI 1.62-13.96; $p=0.0035)$ (Fig. 3).

\section{Impact of BCI results on patient treatment decisions, anxiety, and decision conflict}

Table 2 shows how the BCI results were distributed across the patient self-reported risk categories. When patients were asked about their perceived risk of recurrence before the test results were presented to them, $25 \%$ indicated that their disease was not likely to come back and $74 \%$ felt that it was somewhat likely that it could come back (Table 2). Moreover, after BCI results were discussed with patients, $50 \%$ felt that their disease was not likely to come back, which represents a significant increase $(\mathrm{OR}=9.0 ; 95 \%$ CI $2.73-29.67 ; p<0.0001)$, whereas a significantly reduced number of patients (43\%) thought it was somewhat likely that it could come back $(\mathrm{OR}=0.091 ; 95 \% \mathrm{CI}$ 0.028-0.296; $p<0.0001)$. Six patients changed their risk perception to high risk. Following discussion of BCI test results with their physicians, $29 \%$ fewer patients intended to pursue extended endocrine therapy (58 vs. 82; $\mathrm{OR}=0.077 ; 95 \%$ CI $0.018-0.324 ; p<0.0001)$ and significantly more patients felt strongly comfortable with their decision (51 vs. $26 ; \mathrm{OR}=3.78 ; 95 \%$ CI $1.81-7.88$; $p=0.0003$; Fig. 3).

Mean STAI scores decreased from 31.3 before BCI testing to 29.1 following testing, a significant reduction in overall anxiety level (paired $t$ test $\mathrm{p}$-value $=0.031$ ). At the individual patient level, anxiety level decreased in 54 patients, remained stable in 12 patients, and increased in 30 patients (Fig. 4). Mean DCS scores also improved following BCI testing (20.9 to 10.8; paired $t$ test $p<0.001$ ). At the individual patient level, decision conflict decreased in 62 patients, remained stable in 18 patients, and increased in 16 patients (Fig. 4; supplementary Table 2). Sixty-nine percent of patients reported that knowing BCI test results made them more likely to be compliant with extended endocrine therapy. 
Table 2 Subjective risk estimates of patients and physicians versus the Breast Cancer Index (BCI) risk prediction results

\begin{tabular}{|c|c|c|c|c|}
\hline \multirow{2}{*}{$\begin{array}{l}\text { Pre-test recurrence risk perception (risk of relapse } \\
\text { after } 5 \text { years of endocrine treatment) }\end{array}$} & \multirow{2}{*}{$\begin{array}{l}\text { Number of } \\
\text { patients (\% total) }\end{array}$} & \multicolumn{3}{|c|}{ Patients in Breast Cancer Index (BCI) risk groups ( $\%$ in risk category) } \\
\hline & & Low risk & Intermediate risk & High risk \\
\hline \multicolumn{5}{|l|}{ By physicians } \\
\hline Low risk $(0-5 \%)$ & $47(49)$ & $35(75)$ & $10(31)$ & $2(4)$ \\
\hline Intermediate $(6-15 \%)$ & $37(38)$ & $18(49)$ & $9(24)$ & $10(27)$ \\
\hline High $(>15 \%)$ & $12(13)$ & $4(33)$ & $4(33)$ & $4(34)$ \\
\hline Total & $96(100)$ & $57(59)$ & $23(24)$ & $16(17)$ \\
\hline \multicolumn{5}{|l|}{ By patients } \\
\hline Not at all likely & $24(25)$ & $17(71)$ & $5(21)$ & $2(8)$ \\
\hline Somewhat likely & $71(74)$ & $39(55)$ & $18(25)$ & $14(20)$ \\
\hline Very likely & $1(1)$ & $1(100)$ & 0 & 0 \\
\hline Total & 96 (100) & $57(59)$ & $23(24)$ & $16(17)$ \\
\hline
\end{tabular}

Fig. 2 Medical oncologists' pre- and post-test recommendation for extended adjuvant endocrine treatment

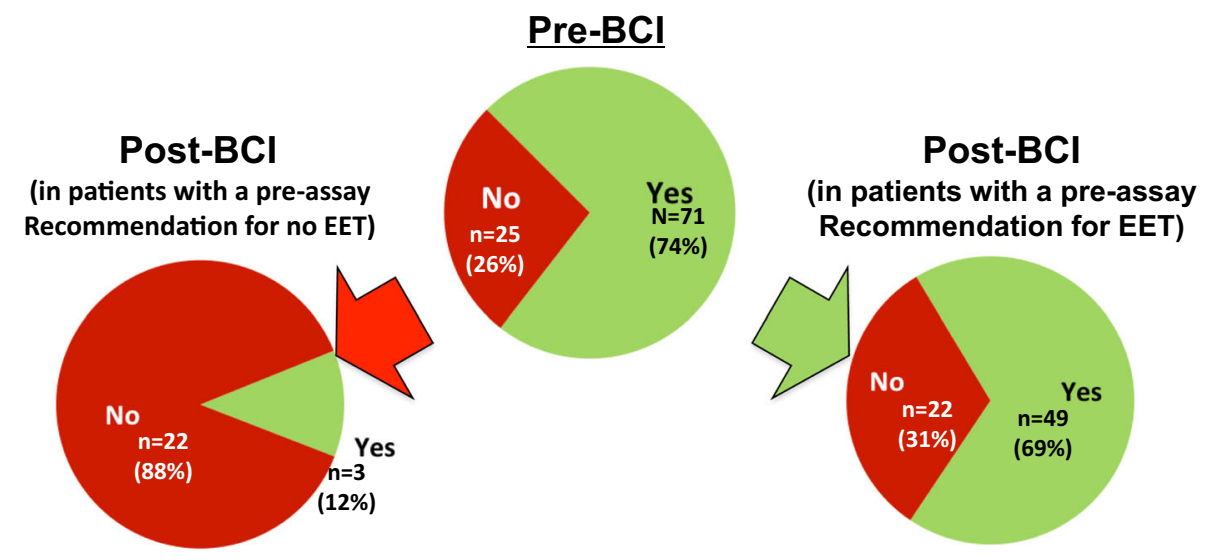

Fig. 3 Medical oncologists' pre-test and post-test level of confidence in treatment recommendation stratified based on whether extended endocrine treatment was recommended in the pre-test and post-test setting (a). Patients' pre-test and posttest levels of comfort with the decision for extended adjuvant endocrine treatment stratified based on whether patients preferred extended endocrine treatment in the pre-test and post-test setting (b)

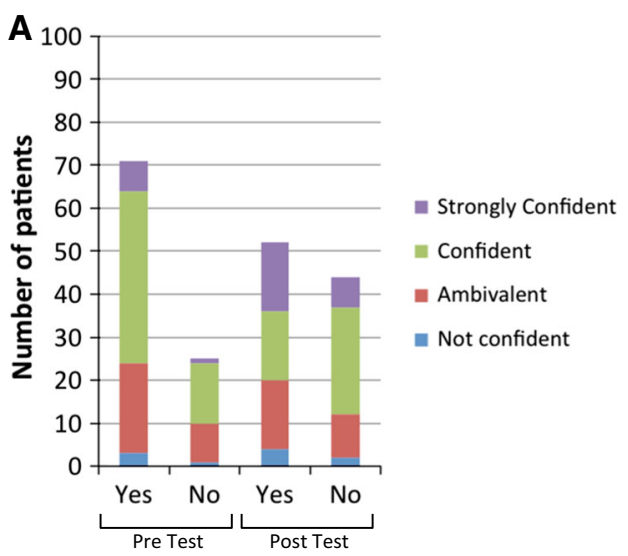

Extended Endocrine Treatment Recommendation
B

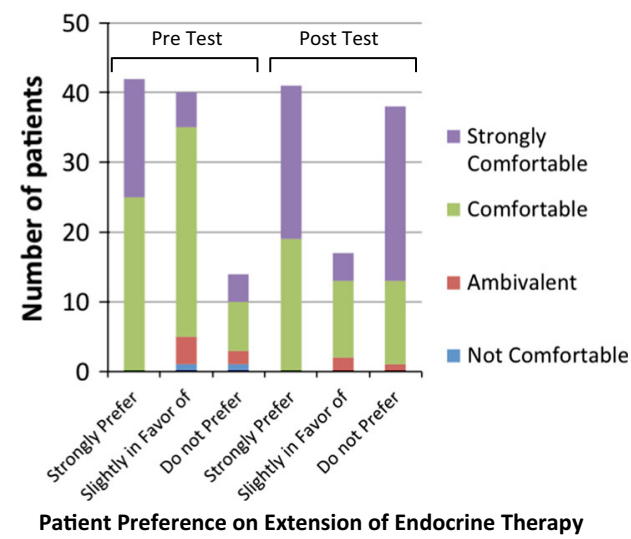


Fig. 4 STAI (a) and DCS (b) scores for individual patients before and after BCI assay. Each line connects the pre- and post-test STAI and DCS scores for an individual $(n=96$ patients). Increasing values post-test are shown in blue and decreasing values are shown in red. $n$ number of the patients, STAI state trait anxiety index, $D C S$ decision conflict scale, $B C I$ Breast Cancer Index

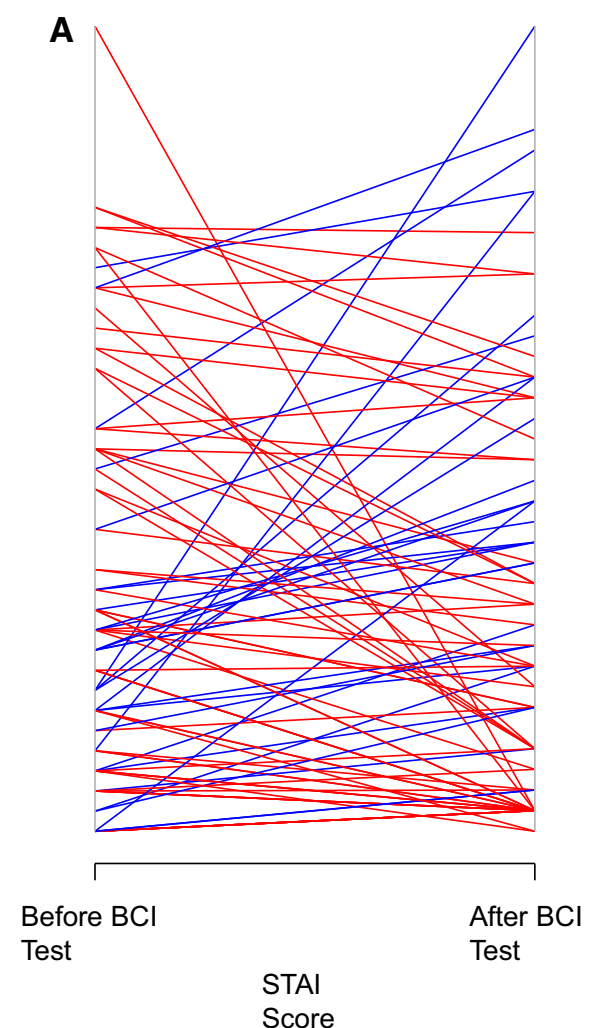

\section{Discussion}

This is the first study to prospectively assess the decisionmaking impact of BCI assay in a routine clinical practice setting in patients who face the decision to continue with extended adjuvant endocrine therapy or stop at 5 years. The results indicate that the test results had a significant effect on both physician treatment recommendation and patient satisfaction. Overall, knowledge of the BCI result led to fewer recommendations for extended endocrine therapy and improved patient satisfaction, and reduced anxiety and decision conflict. We noted that the physicians default tendency was to recommend extended endocrine therapy, consistent with ASCO guidelines and randomized clinical trial results, and patients also favored longer duration of therapy (presumably preferring to err on the cautionary side with potential to reduce the risk of cancer recurrence). This observation is consistent with a recent report that also found that $64 \%$ of physicians recommended extended adjuvant endocrine therapy for eligible patient and $85 \%$ of patients have accepted the recommended treatment [29]. The study results suggest that these choices may be largely based on inflated risk perception. Before testing, $75 \%$ of patients thought that their cancer is very likely or somewhat likely to recur compared to $50 \%$ after the test results became available. Physician estimation of risk of late recurrence was also frequently discordant with the molecular risk assessment result. Prior to knowing the BCI test results, physicians estimated a high risk of recurrence $(>16 \%)$ in 12 patients $(13 \%)$. Of these patients, the BCI test was high risk in $33 \%$, intermediate in $33 \%$, and low in $33 \%$. In two cases, the low-risk category results lead to recommendations to forgo extended endocrine therapy. Conversely, $49 \%$ of those estimated by physicians to have an intermediate $(6-15 \%)$ risk of recurrence had a low risk BCI. The net effect of testing was a decreased perception of risk of late recurrence and reduced recommendation rate for extended endocrine therapy. As expected, when a therapeutic decision is supported by a test result that is perceived as objective, the comfort level with the treatment recommendation increases for both physicians and patients. However, when the clinical risk estimate and molecular risk estimate are widely discordant, this could increase anxiety and ambivalence, which we also observed in a minority of cases.

The results of this study are relevant within the context of the evolving standard of chronic care for patients with early-stage ER-positive breast cancer. Following the completion of the landmark extended adjuvant endocrine therapy trials, more patients are being recommended for 10 years of adjuvant endocrine therapy; however, without patient selection, the number-needed-to-treat is high. Assessment of risk vs benefit, particularly for patients with favorable prognostic features [11], must balance the 
likelihood of benefit from extended therapy against the potential for serious toxicities, tolerability, and quality of life considerations. The findings herein suggest that integrating validated genomic information to help stratify patients based on individualized risk of late recurrence and likelihood of benefit from extended endocrine therapy impacted risk vs benefit discussions and treatment recommendations. Finally, these results may have implications in the context of survivorship program initiatives [30], as a greater proportion of patients reported strong comfort with their treatment decisions as well as reductions in patient anxiety and decision conflict.

This study has several limitations. First, we did not regulate the nature of information exchange between physicians and patients, but recognize that how the test results were communicated could have impacted patient perception about its value. This limitation can also be perceived as a practical strength since the results reflect the outcome of typical patient-physician interactions as they take place in the clinic. This study does not address the prognostic and predictive accuracy of the BCI test, which has been published in a series of peer-reviewed manuscripts previously $[14,19,20]$. The patient population was mostly Caucasian and from an academic medical center which may limit the generalizability of the results.

In summary, extended endocrine therapy decisionmaking has been challenging, given the high number of patients needed to treat in order to obtain benefit and the well-established safety and tolerability challenges with endocrine therapies [11]. Incorporation of BCI assay testing led to altered medical recommendation in $26 \%$ of cases, fewer recommendations for extended endocrine therapy, and improved patient satisfaction.

\begin{abstract}
Author Contributions TS, LP, BS, CH, CS, and BA conceived the study, participated in the design, and drafted the manuscript. $\mathrm{CH}$ and BA conducted the data analysis. VB, MD, MA, GC, AS, EH, SM, and LE played a significant role in the acquisition of data, interpretation of data, revised the manuscript critically for important intellectual content. All authors played a role in study design or acquisition of data, and all participated in manuscript composition or revision. All authors read and approved the final manuscript.
\end{abstract}

\section{Compliance with ethical standards}

Conflict of interest No competing interest including financial interests, activities, relationships, and affiliations to disclose for the following authors: Tara Sanft, MD, Bilge Aktas, MD, Veerle Bossuyt, MD, Michael DiGiovanna, MD, PhD, Maysa Abu-Khalaf, MD, Gina Chung, MD, Andrea Silber, MD, Erin Hofstatter, MD, Sarah Mougalian, MD, Lianne Epstein, MPH, Christos Hatzis, PhD. The following authors disclose competing interests: Brock Schroeder: BioTheranostics employee and stockholder; Cathy Schnabel, MD, PhD: BioTheranostics employee and stockholder; Lajos Pusztai, MD, $\mathrm{PhD}$ : honorarium from BioTheranostics.
Open Access This article is distributed under the terms of the Creative Commons Attribution-NonCommercial 4.0 International License (http://creativecommons.org/licenses/by-nc/4.0/), which permits any noncommercial use, distribution, and reproduction in any medium, provided you give appropriate credit to the original author(s) and the source, provide a link to the Creative Commons license, and indicate if changes were made.

\section{References}

1. Early Breast Cancer Trialists' Collaborative G (2005) Effects of chemotherapy and hormonal therapy for early breast cancer on recurrence and 15-year survival: an overview of the randomised trials. Lancet 365(9472):1687-1717

2. Jin H, Tu D, Zhao N, Shepherd LE, Goss PE (2012) Longer-term outcomes of letrozole versus placebo after 5 years of tamoxifen in the NCIC CTG MA.17 trial: analyses adjusting for treatment crossover. J Clin Oncol Off J Am Soc Clin Oncol 30(7):718-721

3. Goss PE, Ingle JN, Martino S, Robert NJ, Muss HB, Piccart MJ, Castiglione M, Tu D, Shepherd LE, Pritchard KI et al (2003) A randomized trial of letrozole in postmenopausal women after 5 years of tamoxifen therapy for early-stage breast cancer. N Engl J Med 349(19):1793-1802

4. Goss PE, Ingle JN, Martino S, Robert NJ, Muss HB, Piccart MJ, Castiglione M, Tu D, Shepherd LE, Pritchard KI et al (2005) Randomized trial of letrozole following tamoxifen as extended adjuvant therapy in receptor-positive breast cancer: updated findings from NCIC CTG MA.17. J Natl Cancer Inst 97(17):1262-1271

5. Mamounas EP, Jeong JH, Wickerham DL, Smith RE, Ganz PA, Land SR, Eisen A, Fehrenbacher L, Farrar WB, Atkins JN et al (2008) Benefit from exemestane as extended adjuvant therapy after 5 years of adjuvant tamoxifen: intention-to-treat analysis of the National Surgical Adjuvant Breast And Bowel Project B-33 trial. J Clin Oncol Off J Am Soc Clin Oncol 26(12):1965-1971

6. Jakesz R, Greil R, Gnant M, Schmid M, Kwasny W, Kubista E, Mlineritsch B, Tausch C, Stierer M, Hofbauer F et al (2007) Extended adjuvant therapy with anastrozole among postmenopausal breast cancer patients: results from the randomized Austrian Breast and Colorectal Cancer Study Group Trial 6a. J Natl Cancer Inst 99(24):1845-1853

7. Davies C, Pan H, Godwin J, Gray R, Arriagada R, Raina V, Abraham M, Medeiros Alencar VH, Badran A, Bonfill X et al (2013) Long-term effects of continuing adjuvant tamoxifen to 10 years versus stopping at 5 years after diagnosis of oestrogen receptor-positive breast cancer: ATLAS, a randomised trial. Lancet 381(9869):805-816

8. Gray RG, Rea D, Handley K, Bowden SJ, Perry P, Earl HM, Poole CJ, Bates T, Chetiyawardana S, Dewar JA et al (2013) aTTom: long-term effects of continuing adjuvant tamoxifen to 10 years versus stopping at 5 years in 6,953 women with early breast cancer. J Clin Oncol 31(18)

9. Early Breast Cancer Trialists' Collaborative G, Davies C, Godwin J, Gray R, Clarke M, Cutter D, Darby S, McGale P, Pan HC, Taylor C et al (2011) Relevance of breast cancer hormone receptors and other factors to the efficacy of adjuvant tamoxifen: patient-level meta-analysis of randomised trials. Lancet 378(9793):771-784

10. Baum M, Buzdar A, Cuzick J, Forbes J, Houghton J, Howell A, Sahmoud T, Group AT (2003) Anastrozole alone or in combination with tamoxifen versus tamoxifen alone for adjuvant treatment of postmenopausal women with early-stage breast cancer: results of the ATAC (Arimidex, Tamoxifen Alone or in 
Combination) trial efficacy and safety update analyses. Cancer 98(9):1802-1810

11. Burstein HJ, Temin S, Anderson H, Buchholz TA, Davidson NE, Gelmon KE, Giordano SH, Hudis CA, Rowden D, Solky AJ et al (2014) Adjuvant endocrine therapy for women with hormone receptor-positive breast cancer: American Society of Clinical Oncology clinical practice guideline focused update. J Clin Oncol Off J Am Soc Clin Oncol 32(21):2255-2269

12. Hershman DL (2015) Perfecting breast-cancer treatment-incremental gains and musculoskeletal pains. $\mathrm{N}$ Engl $\mathrm{J}$ Med 372(5):477-478

13. Olivotto IA, Bajdik CD, Ravdin PM, Speers CH, Coldman AJ, Norris BD, Davis GJ, Chia SK, Gelmon KA (2005) Populationbased validation of the prognostic model ADJUVANT! for early breast cancer. J Clin Oncol Off J Am Soc Clin Oncol 23(12):2716-2725

14. Sgroi DC, Carney E, Zarrella E, Steffel L, Binns SN, Finkelstein DM, Szymonifka J, Bhan AK, Shepherd LE, Zhang Y et al (2013) Prediction of late disease recurrence and extended adjuvant letrozole benefit by the HOXB13/IL17BR biomarker. J Natl Cancer Inst 105(14):1036-1042

15. Albain KS, Barlow WE, Shak S, Hortobagyi GN, Livingston RB, Yeh IT, Ravdin P, Bugarini R, Baehner FL, Davidson NE et al (2010) Prognostic and predictive value of the 21-gene recurrence score assay in postmenopausal women with node-positive, oestrogen-receptor-positive breast cancer on chemotherapy: a retrospective analysis of a randomised trial. Lancet Oncol 11(1):55-65

16. Desmedt C, Piette F, Loi S, Wang Y, Lallemand F, Haibe-Kains B, Viale G, Delorenzi M, Zhang Y, d'Assignies MS et al (2007) Strong time dependence of the 76-gene prognostic signature for node-negative breast cancer patients in the TRANSBIG multicenter independent validation series. Clin Cancer Res Off J Am Assoc Cancer Res 13(11):3207-3214

17. Buyse M, Loi S, van't Veer L, Viale G, Delorenzi M, Glas AM, d'Assignies MS, Bergh J, Lidereau R, Ellis P et al (2006) Validation and clinical utility of a 70-gene prognostic signature for women with node-negative breast cancer. J Natl Cancer Inst 98(17):1183-1192

18. Lau KF (2009) Time dependence of prognostic values of geneexpression signaturesfor breast cancer. J Clin Oncol Off $\mathbf{J}$ Am Soc Clin Oncol 27(suppl abstr 11085)

19. Zhang Y, Schnabel CA, Schroeder BE, Jerevall PL, Jankowitz RC, Fornander T, Stal O, Brufsky AM, Sgroi D, Erlander MG (2013) Breast Cancer Index identifies early-stage estrogen receptor-positive breast cancer patients at risk for early- and latedistant recurrence. Clin Cancer Res Off J Am Assoc Cancer Res 19(15):4196-4205

20. Sgroi DC, Sestak I, Cuzick J, Zhang Y, Schnabel CA, Schroeder B, Erlander MG, Dunbier A, Sidhu K, Lopez-Knowles E et al
(2013) Prediction of late distant recurrence in patients with oestrogen-receptor-positive breast cancer: a prospective comparison of the breast-cancer index (BCI) assay, 21-gene recurrence score, and IHC4 in the TransATAC study population. Lancet Oncol 14(11):1067-1076

21. Dubsky P, Brase JC, Jakesz R, Rudas M, Singer CF, Greil R, Dietze O, Luisser I, Klug E, Sedivy R et al (2013) The EndoPredict score provides prognostic information on late distant metastases in ER +/HER2- breast cancer patients. Br J Cancer 109(12):2959-2964

22. Sestak I, Cuzick J, Dowsett M, Lopez-Knowles E, Filipits M, Dubsky P, Cowens JW, Ferree S, Schaper C, Fesl C et al (2015) Prediction of late distant recurrence after 5 years of endocrine treatment: a combined analysis of patients from the Austrian breast and colorectal cancer study group 8 and arimidex, tamoxifen alone or in combination randomized trials using the PAM50 risk of recurrence score. J Clin Oncol Off J Am Soc Clin Oncol 33(8):916-922

23. Sgroi DC, Sestak I, Zhang Y, Erlander ME, Schnabel CA, Goss PE, Cuzick J, Dowsett M (2012) Evaluation of prognostic and predictive performance of Breast Cancer Index and its components in hormonal receptor-positive breast cancer patients: a TransATAC study. Cancer Res 72 (Suppl.) Abstract nr P2-10-15

24. State-Trait Anxiety Inventory for Adults Manual, Instrument and Scoring Guide

25. O'Connor AM (1995) Validation of a decisional conflict scale. Med Decis Mak Int J Soc Med Decis Mak 15(1):25-30

26. Ma XJ, Wang Z, Ryan PD, Isakoff SJ, Barmettler A, Fuller A, Muir B, Mohapatra G, Salunga R, Tuggle JT et al (2004) A twogene expression ratio predicts clinical outcome in breast cancer patients treated with tamoxifen. Cancer Cell 5(6):607-616

27. Ma XJ, Salunga R, Dahiya S, Wang W, Carney E, Durbecq V, Harris A, Goss P, Sotiriou C, Erlander M et al (2008) A five-gene molecular grade index and HOXB13:IL17BR are complementary prognostic factors in early stage breast cancer. Clin Cancer Res Off J Am Assoc Cancer Res 14(9):2601-2608

28. Lo SS, Mumby PB, Norton J, Rychlik K, Smerage J, Kash J, Chew HK, Gaynor ER, Hayes DF, Epstein A et al (2010) Prospective multicenter study of the impact of the 21-gene recurrence score assay on medical oncologist and patient adjuvant breast cancer treatment selection. J Clin Oncol Off J Am Soc Clin Oncol 28(10):1671-1676

29. Myrick ME, Schmid SM, Kilic N, Guth U (2012) Eligibility, compliance and persistence of extended adjuvant endocrine therapy for breast cancer. Acta Oncol 51(2):247-253

30. Providing High Quality Survivorship Care in Practice: An ASCO Guide http://www.asco.org/sites/www.asco.org/files/survivorcom pendium2014_web.pdf 